\title{
Correlations Between Vertical Ground Reaction Force, Sagittal Joint Angles, and the Muscle Co-Contraction Index During Single-Leg Jump-Landing
}

\author{
Shunsuke Ohji ${ }^{1,{ }^{*}}$, Junya Aizawa ${ }^{1}$, Kenji Hirohata ${ }^{1}$, Takehiro Ohmi ${ }^{1}$ and Kazuyoshi Yagishita ${ }^{1}$ \\ ${ }^{1}$ Clinical Center for Sports Medicine and Sports Dentistry, Tokyo Medical and Dental University, Tokyo, Japan \\ "Corresponding author: Clinical Center for Sports Medicine and Sports Dentistry, Tokyo Medical and Dental University, Tokyo, Japan. Email: ohji.spt@tmd.ac.jp
}

Received 2018 July 06; Revised 2018 November 19; Accepted 2019 May 17.

\begin{abstract}
Background: Impact and lower extremity joint angles during landing are factors that can increase the risk of anterior cruciate ligament injuries. However, the correlations between these factors and lower extremity muscle activation during the flight phase, which may affect these factors, are unknown.

Objectives: The present study aimed to clarify the correlations between the peak vertical ground reaction force (pVGRF), sagittal joint angles during the landing phase, and the vastus medialis (VM) and semitendinosus (ST) muscle co-contraction index (CCI) during the flight phase in single-leg jump-landing.

Methods: Fourteen healthy, physically active volunteers (age, $22.6 \pm 2.7$ years; height, $164.4 \pm 7.6 \mathrm{~cm}$; body weight, $58.9 \pm 8.9 \mathrm{~kg}$; body mass index, $21.7 \pm 2.3 \mathrm{~kg} / \mathrm{m}^{2}$ ) participated. All subjects performed a single-leg jump-landing task. The pVGRF variables and the sagittal joint angles during the landing phase were measured. The CCI between the VM and ST during the flight phase was measured. The correlations between the VGRF variables, sagittal joint angles, and CCI were assessed using Spearman's rank correlation coefficient.

Results: The knee flexion angle at the PVGRF was negatively correlated with the magnitude of pVGRF $(\rho=-0.609, \mathrm{P}=0.021)$. The knee flexion angle at the PVGRF was negatively correlated with the CCI during the flight phase in single-leg jump-landing $(\rho=-0.627, \mathrm{P}=$ $0.016)$.

Conclusions: An excessive CCI between the VM and ST during the flight phase might be indirectly related to a greater landing impact after a single-leg jump.
\end{abstract}

Keywords: Anterior Cruciate Ligament, Before Landing, Co-Activation, Impact Absorption

\section{Background}

Non-contact anterior cruciate ligament (ACL) injury often occurs during decelerating movements such as singleleg landing after jumping (1). The timing and magnitude of the peak vertical ground reaction force (pVGRF), which represents the landing impact force, might increase the risk of ACL injury (2-5). During single-leg landing, ACL strain was shown to peak at the instant of the pVGRF (2). The pVGRF correlates positively with the proximal tibial anterior shear force and the knee extension internal moment, both of which increase ACL strain (3). A prospective study demonstrated that the pVGRF during doubleleg drop landing is 20\% higher in female athletes who had sustained ACL injuries than in those who had not (4). Research has shown that deceasing the pVGRF magnitude and controlling the time from initial contact(IC) to the pV-
GRF (time to pVGRF) are important to avoid the excessive ACL strain that leads to ACL injury during landing $(5,6)$.

The pVGRF changes based on the sagittal joint angle of the lower extremity during landing (7-10). During singleleg landing, smaller knee and hip flexion angles $(9,10)$ and smaller ankle dorsiflexion angles $(11,12)$ generate larger $\mathrm{pV}$ GRF magnitudes. It has been reported that the PVGRF is smaller during a landing when subjects consciously bend the knee and hip than during a natural landing $(8,13)$.

During landing, the co-contraction index (CCI) between the quadriceps and hamstrings tends to correlate with the sagittal joint angle of the lower extremity in healthy subjects and patients with reconstructed ACLs (14, 15). In healthy individuals, the CCI between the quadriceps and hamstrings after landing is significantly greater when the knee flexion angle is restricted to $0^{\circ}-25^{\circ}$ compared to 
$25^{\circ}-50^{\circ}$ or $50^{\circ}-75^{\circ}(14)$. Compared to healthy subjects, patients with reconstructed ACLs have smaller knee flexion angles and a higher CCI between the quadriceps and hamstrings during landing (15).

Feed-forward activation, a type of neuromuscular control, occurs during the flight phase $(16,17)$. For instance, during double-leg landing, activation of the lower extremity muscles occurs approximately $80 \mathrm{~ms}$ before foot contact (16). Studies have demonstrated that the quadriceps and hamstrings contract simultaneously during the flight phase $(18,19)$. Feed-forward co-contraction during the flight phase is believed to contribute to control of the joint angle and the pVGRF during landing $(16,20)$. However, the correlations between the CCI, sagittal joint angles, and the pVGRF from the flight phase to the landing phase have not been analyzed.

\section{Objectives}

The purposes of this study were to clarify how the sagittal joint angle correlates with the pVGRF during the landing phase and how the CCI during the flight phase correlates with the sagittal angle during the landing phase in a single-leg jump-landing task. We hypothesized that the pVGRF is negatively correlated with the knee flexion angle during the landing phase. We furthermore hypothesized that the knee flexion angle during the landing phase is negatively correlated with flight-phase CCI.

\section{Methods}

\subsection{Subjects}

The inclusion criteria were as follows: physically active, at least 18 years of age, and without a history of serious injury or surgery involving the lower extremities or lumbar region. Seven women and seven men participated in this study. The subjects' characteristics (mean \pm standard deviation) were as follows: age, $22.6 \pm 2.7$ years; height, 164.4 $\pm 7.6 \mathrm{~cm}$; body weight, $58.9 \pm 8.9 \mathrm{~kg}$; and body mass index, $21.7 \pm 2.3 \mathrm{~kg} / \mathrm{m}^{2}$. The subjects usually participated in sports such as soccer, handball, tennis, volleyball, and rugby that involve jump-landing and abrupt turns and stops. The dominant leg was defined as the leg used to kick a ball for the maximum distance (21). One of the 14 subjects was left-leg dominant. The sample size was calculated to be 14 subjects using $G^{*}$ power statistical software (alpha $=0.05$, power $=0.8$, two-tailed) with reference to the correlation coefficient between pVGRF and the knee flexion angle during single-leg jump landing $(9,22)$. All subjects read and signed an approved informed consent document before data collection. This study was approved by the university's institutional review board.

\subsection{Equipment Protocol}

All subjects were clothed in identical athletic attire comprising spandex shirts, shorts, and shoes with no air cushions (step101, Lucky Bell, Kobe, Japan). They performed active static stretching (23) and no-load ergometer pedaling for 5 minutes as a warm-up before measurements. To obtain kinematic data, reflective markers (diameter, $14 \mathrm{~mm}$ ) were attached to the anterior superior iliac spine(ASIS), posterior superior iliac spine(PSIS), greater trochanter (GT), lateral joint space (LJS) at the midpoint of the knee, lateral malleolus of the fibula, and head of the fifth metatarsal based on the landmarks reported in a previous study (24). A 25-cm-high step (RBK-BO001, Reebok, Canton, MA, USA) was placed $60 \mathrm{~cm}$ from the center of the force plate (22). The height of the force plate surface was $5 \mathrm{~cm}$ above the ground level. The lower extremity joint angles during jump landing were recorded using a highspeed camera (120 Hz, GC-P100, JVC, Yokohama, Japan). The high-speed camera was placed with the lens $335 \mathrm{~cm}$ from the center of the force plate, perpendicular to the plane of motion, to record sagittal plane joint angles $(22,25)$. The height of the camera was $1 \mathrm{~m}$ from the center of the lens to the floor. Videographic and force plate data were time synchronized using a synchronizer (PTS-110/2 LED, DKH, Tokyo, Japan).

\subsection{Procedures}

All subjects performed a single-leg jump-landing task with their dominant leg. They stood on the step on their dominant leg with the other knee bent at up to $90^{\circ}$, neutral hip rotation, arms crossed, and hands inserted into the opposite axillae to eliminate the effect of arm movement. All subjects jumped forward without intentional upward action and landed as naturally as possible on the center of the force plate and maintained balance for 5 seconds. A trial was deemed unacceptable if the arms left the chest, part of the sole of the foot fell outside the force plate at landing, the foot moved or slid after landing, and/or if the sole of the opposite foot touched the force plate or floor. All subjects practiced three single-leg jump-landing tasks before data collection.

The VGRF data were recorded using a force plate (260AA6, Kistler Instrument AG, Winterthur, Switzerland) at a sampling rate of $1000 \mathrm{~Hz}$ using the software (IFS-4J/3], DKH). The VGRF data were filtered through a fourth-order Butterworth low-pass digital filter at a cut-off frequency of $50 \mathrm{~Hz}$ and normalized by body weight. Extracted VGRF data included the magnitude of the PVGRF and the time to pVGRF. The IC was defined as the moment when VGRF exceeded $10 \mathrm{~N}$ (26). The pVGRF has demonstrated acceptable test-retest reliability during single-leg jump-landing (27). 
The sagittal joint angles were measured on extracted video frames. The angles of anterior pelvic tilt, hip flexion, knee flexion, and ankle dorsiflexion were measured as the sagittal joint angles at the timing of the pVGRF. The sagittal joint angles that were indicated by markers in each frame were measured using ImageJ (National Institutes of Health, Bethesda, MD, USA). Anterior pelvic tilt was defined as the angle formed between a line joining the ASIS and PSIS. The hip flexion angle was defined as the angle added to the anterior pelvic tilt to thigh angle from a vertical line relative to the floor. The knee flexion angle was defined as the angle obtained by subtracting a line joining the GT and LJS at the midpoint of the knee and lateral malleolus of the fibula from a line extending between the GT and LJS. The ankle dorsiflexion angle was defined as the angle formed between a line joining the LJS with the lateral malleolus of the fibula and the head of the fifth metatarsal. Although the anterior pelvic tilt and ankle dorsiflexion angles may appear to be in ankle dorsiflexion or anterior pelvic tilt positions, they may have shifted in the plantar flexion or posterior tilt directions compared to the stationary standing position. Thus, these two angles were subtracted from the standing position. The sagittal joint angles using two-dimensional analysis have demonstrated acceptable intrarater and test-retest reliability during landing $(28,29)$.

The muscular activation data were obtained by surface electromyography (EMG; WEB-1000, Nihon Kohden, Tokyo, Japan) and recorded at $1000 \mathrm{~Hz}$ with band-pass filtering $(20-500 \mathrm{~Hz})$ on a personal computer (CC-700H, Nihon Kohden) using a receiver (ZR-100H, Nihon Kohden). The skin was cleaned with alcohol before surface electrodes (ZB-150H, Nihon Kohden) for EMG recordings were applied. The specifications of the electrodes were as follows: size, 25 $\times 34.5 \times 12 \mathrm{~mm}^{3}$; weight, 10 g; electrode size, $10 \times 2 \mathrm{~mm}^{2}$; interelectrode distance, $5 \mathrm{~mm}$. The surface electrodes were applied to the vastus medialis (VM) and semitendinosus (ST) according to the method of the Surface ElectroMyoGraphy for the Non-Invasive Assessment of Muscles project (30).

Prior to collecting the data during the landing task, EMG data were recorded during maximum voluntary isometric contraction (MVIC) of both the VM and ST (30). The MVIC was performed for 3 seconds. The root-mean-square (RMS) amplitudes were calculated using a 100-ms window, and the highest averaged RMS amplitudes were defined as the MVIC.

The RMS amplitudes during the landing task were normalized by MVIC (\%MVIC). The VM and ST activations during the flight phase were analyzed using the \%MVIC data. The flight phase was defined as $100 \mathrm{~ms}$ before landing to the IC $(20,22,31,32)$. Co-contraction between the VM and
ST during the flight phase was extracted and calculated using the co-contraction index (CCI), as recommended by Falconer and Winter $(19,33)$. The following equation was used:

$C C I=\frac{2 I_{a n t}}{I_{\text {total }}} \times 100 \%$

$I_{\text {ant }}$ is the area of the total antagonistic activity and is calculated using the following equation:

$I_{\text {ant }}=\int_{t_{1}}^{t_{2}} E M G_{S T}(t) d t+\int_{t_{2}}^{t_{3}} E M G_{V M}(t) d t$

Where $t_{1}$ and $t_{2}$ denote the period where the ST activations were less than the VM activations, whereas $t_{2}$ and $t_{3}$ denote the period where the VM activations are less than ST activation; $I_{\text {total }}$ is the integral of the sum of ST and VM activations during the landing:

$I_{\text {total }}=\int_{t_{1}}^{t_{3}}\left[E M G_{\text {agon }}+E M G_{\text {ant }}\right](t) d t$

The EMG (\%MVIC) data at $100 \mathrm{~ms}$ and $50 \mathrm{~ms}$ before the IC were also extracted. EMG is a reliable method for assessing the reproducibility of both quadriceps and hamstrings muscle activation during landing (34).

\subsection{Statistical Analysis}

The correlations between the VGRF variables, sagittal joint angles, and CCI were assessed using Spearman's rank correlation coefficient, rho $(\rho)$. The a priori $\alpha$ level was 0.05. Data were analyzed using SPSS V. 21.0 (IBM Corp, Armonk, NY, USA).

\section{Results}

The results for the kinetics and kinematics variables during single-leg jump-landing are presented in Table 1. The knee flexion angle at the pVGRF was negatively correlated with the $\operatorname{pVGRF}(\rho=-0.609 ; \mathrm{P}=0.021$ ) (Table 2$)$. The knee flexion angle at the pVGRF was negatively correlated with the CCI between the VM and ST during the flight phase ( $\rho=-0.627 ; \mathbf{P}=0.016$ ) (Table 3 ).

Although the hip flexion angle at the PVGRF was negatively correlated with the CCI between the VM and ST during the flight phase $(\rho=-0.550 ; \mathrm{P}=0.042)$, it was not correlated with the $\operatorname{pVGRF}(\rho=-0.290 ; \mathrm{P}=0.923)$. Moreover, although the ankle dorsiflexion angle was positively correlated with the time to $\operatorname{pVGRF}(\rho=0.660 ; \mathrm{P}=0.010)$, it was not correlated with the $\operatorname{pVGRF}(\rho=-0.530 ; \mathrm{P}=0.051)$. 
Table 1. Vertical Ground Reaction Force Variables, Sagittal Joint Angle at Peak Vertical Ground Reaction Force, and Muscular Activation During the Flight Phase in SingleLeg Jump-Landing ${ }^{\mathrm{a}}$

\begin{tabular}{|c|c|}
\hline Variable & $\begin{array}{c}\text { Medium Value } \\
\text { (Interquartile Range) }\end{array}$ \\
\hline \multicolumn{2}{|l|}{ GRF } \\
\hline pVGRF (\%BW) & $371.7(316.8-399.9)$ \\
\hline Time to pVGRF (ms) & $40.5(36.0-54.3)$ \\
\hline \multicolumn{2}{|l|}{ Joint angle $\left({ }^{\circ}\right)$} \\
\hline Hip flexion & $34.1(26.1-36.5)$ \\
\hline Knee flexion & $44.2(35.7-47.7)$ \\
\hline Ankle dorsiflexion & $7.4(4.7-15.1)$ \\
\hline \multicolumn{2}{|l|}{ Muscular activation (\%) } \\
\hline VM at $100 \mathrm{~ms}$ before-landing & $40.9(26.2-70.4)$ \\
\hline VM at $50 \mathrm{~ms}$ before-landing & $66.3(35.8-103.6)$ \\
\hline ST at $100 \mathrm{~ms}$ before-landing & $27.1(15.6-39.2)$ \\
\hline ST at $50 \mathrm{~ms}$ before-landing & $37.9(21.4-62.1)$ \\
\hline CCI between VM and ST & $78.9(66.2-87.1)$ \\
\hline
\end{tabular}

Abbreviations: BW, body weight; CCI, co-contraction index; IC, initial contact; pVGRF, peak vertical ground reaction force; ST, semitendinosus; Time to pVGRF, time from initial contact to pVGRF; VM, vastus medialis.

${ }^{\mathrm{a}}$ The EMG of each muscle was expressed as a percentage of the EMG value during the maximum voluntary isometric contraction.

Table 2. Correlation Coefficients $(\rho)$ Between Ground Reaction Force Variables and Sagittal Joint Angle at Peak Vertical Ground Reaction Force During Single-Leg JumpLanding

\begin{tabular}{ccc}
\hline Variable & pVGRF & Time to pVGRF \\
\hline Joint angle $\left(^{\circ}\right)$ & & \\
Hip flexion & -0.029 & -0.376 \\
\hline Knee flexion & $-0.609^{\mathrm{a}}$ & 0.513 \\
Ankle dorsiflexion & -0.530 & $0.660^{\mathrm{b}}$ \\
\hline
\end{tabular}

Abbreviations: pVGRF, peak vertical ground reaction force; Time to pVGRF, time from initial contact to PVGRF.

${ }^{\mathrm{a}} \mathrm{P}<0.05$.

${ }^{\mathrm{b}} \mathrm{P}<0.01$.

\section{Discussion}

This cross-sectional study analyzed the correlations between single-leg jump-landing kinetics and kinematics in healthy athletes, and the results suggested that the flightphase CCI is indirectly correlated with the pVGRF via the sagittal joint angles.

There was a significant negative correlation between the knee flexion angle at the pVGRF and the pVGRF magnitude. There was also a significant negative correlation between the knee flexion angle at the PVGRF and the CCI during the flight phase. The present study demonstrated that the knee flexion angle during the landing phase decreases as the CCI between the VM and ST increases dur-
Table 3. Correlation Coefficients $(\rho)$ Between Sagittal Joint Angle at Peak Ground Reaction Force and Muscular Activation During the Flight Phase in Single-Leg JumpLanding $^{\mathrm{a}}$

\begin{tabular}{lccc}
\hline Variables & $\begin{array}{c}\text { Hip } \\
\text { Flexion }\end{array}$ & $\begin{array}{c}\text { Knee } \\
\text { Flexion }\end{array}$ & $\begin{array}{c}\text { Ankle } \\
\text { Dorsiflexion }\end{array}$ \\
\hline $\begin{array}{l}\text { VM at 100 ms } \\
\text { before-landing }\end{array}$ & -0.033 & -0.031 & 0.079 \\
$\begin{array}{l}\text { VM at 50 ms } \\
\text { before-landing }\end{array}$ & 0.075 & -0.033 & -0.159 \\
$\begin{array}{l}\text { ST at 100 ms } \\
\text { before-landing }\end{array}$ & 0.112 & -0.095 & -0.015 \\
$\begin{array}{l}\text { ST at 50 ms } \\
\text { before-landing }\end{array}$ & -0.311 & -0.383 & -0.310 \\
\hline \begin{tabular}{l} 
CCI between VM and ST \\
\hline
\end{tabular} & $-0.550^{\mathrm{b}}$ & $-0.627^{\mathrm{b}}$ & -0.495 \\
\hline
\end{tabular}

Abbreviations: CCI, co-contraction index; IC, initial contact; ST, semitendinosus; VM, vastus medialis.

${ }^{\text {a }}$ The EMG of each muscle was expressed as a percentage of the EMG value dur-

ing the maximum voluntary isometric contraction.

${ }^{\mathrm{b}} \mathrm{P}<0.05$

ing the flight phase. Furthermore, the pVGRF increases as the knee flexion angle decreases during the landing phase. These findings support the hypothesis of the present study.

Many experimental studies have clarified that increasing the knee flexion angle is important for impact absorption during landing $(14,35,36)$. Theoretically, an increase in the knee flexion angle is beneficial for impact absorption because the negative work, which indicates the impact absorption energy, increases. In a double-leg landing task, a soft landing with knee flexion angle $\geq 90^{\circ}$, compared to a stiff landing by restricting the knee flexion angle to $\leq 90^{\circ}$, decreases the pVGRF, and the knee flexion angle and negative work affect impact absorption (7). In a single-leg jumplanding task, the maximum knee flexion angle and knee flexion excursion have been shown to affect impact absorption $(8,36)$. Similarly to previous studies, the present study demonstrated that a larger knee flexion angle at the pVGRF is important for impact absorption.

The present study also showed a negative correlation between the knee flexion angle at the pVGRF and the CCI between the VM and ST during the flight phase. The results suggest that excessive co-contraction of the VM and ST during the flight phase may decrease the knee flexion angle during the landing phase. It has been shown in single-leg landing tasks that the CCI between the quadriceps and hamstrings during the landing phase is significantly greater when the knee flexion angle is restricted to $0^{\circ}-25^{\circ}$ compared to $25^{\circ}-50^{\circ}$ or $50^{\circ}-75^{\circ}(14)$. Compared to a preferred landing, a soft landing shows a greater knee flexion angle and a lower CCI between the vastus lateralis and biceps femoris during the landing phase (37). As described here, the CCIs analyzed in previous studies all pertain to the landing phase. Thus, the results from the present study are new data demonstrating the correlation between the CCI during the flight phase and the sagittal joint angle dur- 
ing the landing phase.

Feed-forward muscle activation prepares the lower extremities for impact immediately after landing (38). However, the correlation between the co-contraction between the VM and ST during the flight phase and the impact and lower extremity joint angles during landing had not been clarified. The results of the present study suggest that the co-contraction between the VM and ST during the flight phase is indirectly correlated with the pVGRF via the sagittal angles (Figure 1).

To the best of our knowledge, no other studies have demonstrated the correlation between the flight-phase $\mathrm{CCI}$ and the knee flexion angle at the pVGRF in single-leg jump-landing. In a drop vertical jump, which is a different task than that performed in the present study, knee flexion at initial contact decreases with increasing co-contraction of the quadriceps and hamstrings prior to landing (21). Although the task and the timing of measuring the knee flexion angle are different from the present study, comparable results were obtained. Thus, to the best of our knowledge, there are no reports that contradict the results of the present study.

Although the present study demonstrated a correlation between the flight-phase CCI and the hip flexion angle at the pVGRF, there was no correlation between the hip flexion angle and the pVGRF. A previous study also did not find a correlation between the hip flexion angle at the pVGRF and the pVGRF during single-leg jump-landing (9). Similar results were also reported in single-leg lateral jumplanding (22). Although hip flexion is considered to be important for impact absorption, the extent of its contribution is smaller than that of knee flexion (7). On the other hand, it has been reported that the pVGRF and the maximum hip flexion angle during landing are correlated (10), indicating that the correlation between the hip flexion angle and the pVGRF differs depending on the measurement timing. These findings highlight the importance of focusing on knee flexion rather than hip flexion for the timing of the pVGRF during the landing phase.

This study did not find a correlation between ankle dorsiflexion and the pVGRF. In landing tasks with the toes, dorsiflexion of the foot appears rapidly after contacting the ground in plantar flexion (7), indicating that the ankle could be in plantar flexion or dorsiflexion depending on the measurement timing. It has been shown in single-leg jump-landing, which is the same task used in the present study, that ankle plantar flexion is observed at the pVGRF when the height or distance of the jump is different, unlike the present study's results (9). However, many studies have elucidated the effects of ankle kinematics on impact absorption $(11,12)$, indicating the importance of focusing on various parameters such as measurement timing, as well as moment (7) and displacement during landing (39).

In impact absorption, it is mechanically important to extend the time to pVGRF. The present study showed that the time to pVGRF is extended as the ankle dorsiflexion angle increases. It has been suggested that the time to pVGRF extends when consciously landing with the toes compared to landing with the heel(13). The present study also demonstrated that ankle dorsiflexion at the pVGRF is related to impact absorption.

The time from reaching maximum VGRF after the toes touch the ground to an actual ACL injury is extremely short, at approximately $40 \mathrm{~ms}(1,2)$. It is therefore theoretically difficult to control the sagittal angle and to decrease VGRF simply through voluntary and reflexive feedback control after landing. Furthermore, it is thought that the muscle activation prepares for impact absorption during the flight phase (38). Based on these reasons, the present results can be regarded as data that emphasize the importance of focusing on the flight-phase CCI, from the perspective of impact absorption.

A soft landing while consciously bending the hip and knee is recommended to decrease the $\operatorname{pVGRF}(7,8,13,40)$. In a study in which subjects were instructed to land softly, the knee flexion angle increased and the landing-phase CCI and pVGRF decreased (37). The results of the present study suggested that controlling excessive co-contraction between the VM and ST during the flight phase increases the knee flexion angle during the landing phase. To promote better impact absorption, it may be important to provide instructions to avoid excessively increasing the CCI from the flight phase to landing and stiffening the joints.

\subsection{Limitations}

The present study had some limitations. First, because the CCI is the area of the EMG waveforms from the VM and ST that overlaps, the intensity of the cocontraction could not be ascertained. It has been reported that co-contraction enhances joint stability $(41,42)$ and that co-contraction is necessary for landing depending on the height of the fall (43). However, the effects of cocontraction were not assessed in the present study. Next, the CCI between the knee extensor and flexor muscles is affected by sex, age, and motor skill (44), but these factors were not considered. Last, the knee moment and strain of the ACL were not measured. Therefore, the direct effect that the VGRF variables and sagittal joint angle have on the risk of ACL injury remains unclear.

\subsection{Conclusions}

The CCI between the vastus medialis and semitendinosus during the flight phase may be related indirectly to a 


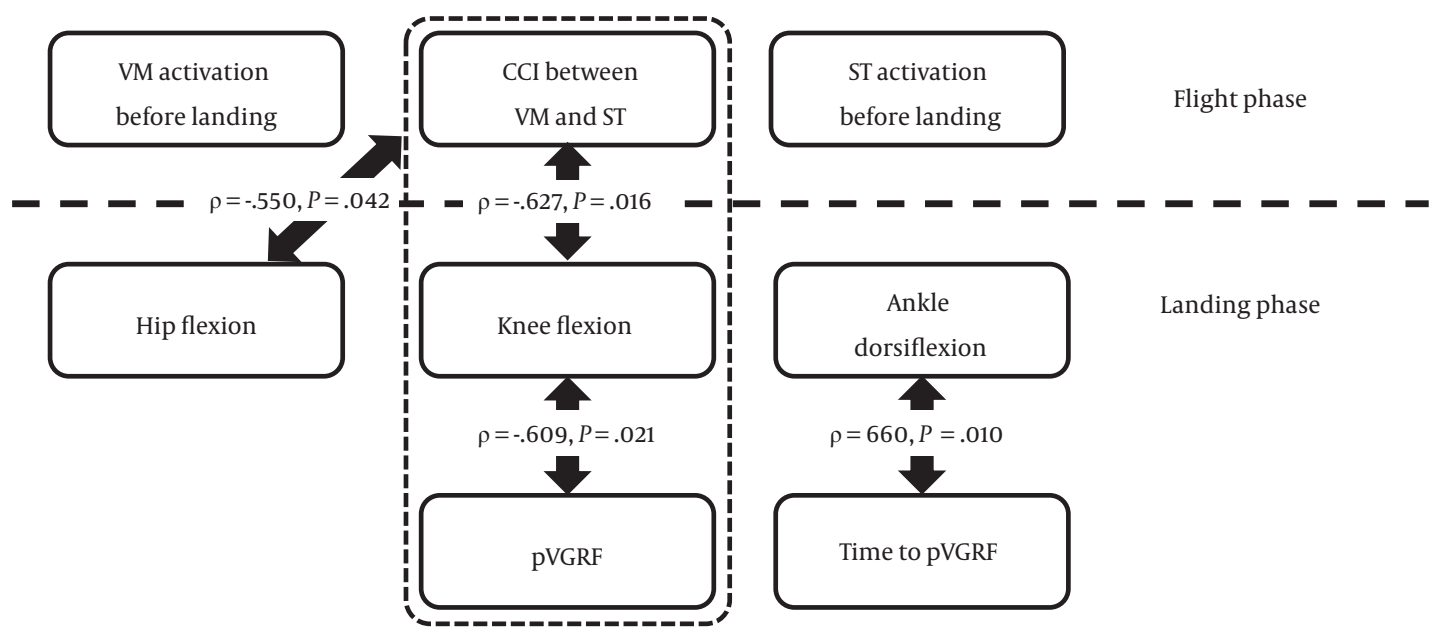

Figure 1. Correlations between the co-contraction index during the flight phase and impact absorption during single-leg jump-landing. The results suggest that the cocontraction between the VM and ST during the flight phase is indirectly correlated with the pVGRF via the sagittal angles. CCI, co-contraction index; pVGRF, peak vertical ground reaction force; ST, Semitendinosus; VM, Vastus medialis.

greater VGRF during single-leg jump-landing. In soft landing instructions to reduce the landing impact, it may be necessary to provide guidance that specifies avoiding excessive increases in the CCI from the flight phase until landing so that the joints do not become stiff.

\section{Footnotes}

Authors' Contribution: Junya Aizawa developed the original idea, drafting of the article, analysis and writing the manuscript. Kenji Hirohata developed the original idea, abstracted data and analysis data. Takehiro Ohmi also developed the original idea, abstracted data and analysis data. Kazuyoshi Yagishita contribute original idea, analysis and final approval of the article. All authors gave me a comment about this resubmission.

Conflict of Interests: It is not declared by the authors.

Ethical Approval: The Institutional Review Board at our institution approved the study design (approval number, 1885).

Funding/Support: It is not declared by the authors.

\section{References}

1. Koga H, Nakamae A, Shima Y, Iwasa J, Myklebust G, Engebretsen L, et al. Mechanisms for noncontact anterior cruciate ligament injuries: Knee joint kinematics in 10 injury situations from female team handball and basketball. Am J Sports Med. 2010;38(11):2218-25. doi: 10.1177/0363546510373570. [PubMed: 20595545].

2. Cerulli G, Benoit DL, Lamontagne M, Caraffa A, Liti A. In vivo anterior cruciate ligament strain behaviour during a rapid deceleration movement: Case report. Knee Surg Sports Traumatol Arthrosc. 2003;11(5):30711. doi: 10.1007/s00167-003-0403-6. [PubMed: 14523613].
3. Yu B, Lin CF, Garrett WE. Lower extremity biomechanics during the landing of a stop-jump task. Clin Biomech (Bristol, Avon). 2006;21(3):297-305. doi: 10.1016/j.clinbiomech.2005.11.003. [PubMed: 16378667].

4. Hewett TE, Myer GD, Ford KR, Heidt RS Jr, Colosimo AJ, McLean SG, et al. Biomechanical measures of neuromuscular control and valgus loading of the knee predict anterior cruciate ligament injury risk in female athletes: A prospective study. Am J Sports Med. 2005;33(4):492501. doi: 10.1177/0363546504269591. [PubMed: 15722287].

5. Padua DA, Distefano LJ. Sagittal plane knee biomechanics and vertical ground reaction forces are modified following ACL injury prevention programs: A systematic review. Sports Health. 2009;1(2):165-73. doi: 10.1177/1941738108330971. [PubMed: 23015868]. [PubMed Central: PMC3445071].

6. Caulfield B, Garrett M. Changes in ground reaction force during jump landing in subjects with functional instability of the ankle joint. Clin Biomech (Bristol, Avon). 2004;19(6):617-21. doi: 10.1016/j.clinbiomech.2004.03.001. [PubMed:15234486].

7. Devita P, Skelly WA. Effect of landing stiffness on joint kinetics and energetics in the lower extremity. Med Sci Sports Exerc. 1992;24(1):10815. [PubMed: 1548984].

8. Blackburn JT, Padua DA. Sagittal-plane trunk position, landing forces, and quadriceps electromyographic activity. J Athl Train. 2009;44(2):174-9. doi: 10.4085/1062-6050-44.2.174. [PubMed: 19295962]. [PubMed Central: PMC2657019].

9. Ali N, Robertson DG, Rouhi G. Sagittal plane body kinematics and kinetics during single-leg landing from increasing vertical heights and horizontal distances: Implications for risk of non-contact ACL injury. Knee. 2014;21(1):38-46. doi:10.1016/j.knee.2012.12.003. [PubMed: 23274067].

10. Ali N, Rouhi G, Robertson G. Gender, vertical height and horizontal distance effects on single-leg landing kinematics: Implications for risk of non-contact ACL injury. J Hum Kinet. 2013;37:27-38. doi: 10.2478/hukin-2013-0022. [PubMed: 24146702]. [PubMed Central: PMC3796838].

11. Mason-Mackay AR, Whatman C, Reid D. The effect of reduced ankle dorsiflexion on lower extremity mechanics during landing: A systematic review. J Sci Med Sport. 2017;20(5):451-8. doi: 10.1016/j.jsams.2015.06.006. [PubMed: 26117159]. 
12. Fong CM, Blackburn JT, Norcross MF, McGrath M, Padua DA. Ankledorsiflexion range of motion and landing biomechanics. J Athl Train. 2011;46(1):5-10. doi: 10.4085/1062-6050-46.1.5. [PubMed: 21214345]. [PubMed Central: PMC3017488].

13. Self BP, Paine D. Ankle biomechanics during four landing techniques. Med Sci Sports Exerc. 2001;33(8):1338-44. [PubMed: 11474336].

14. Podraza JT, White SC. Effect of knee flexion angle on ground reaction forces, knee moments and muscle co-contraction during an impact-like deceleration landing: Implications for the non-contact mechanism of ACL injury. Knee. 2010;17(4):291-5. doi: 10.1016/j.knee.2010.02.013. [PubMed: 20303276].

15. Tsai LC, McLean S, Colletti PM, Powers CM. Greater muscle cocontraction results in increased tibiofemoral compressive forces in females who have undergone anterior cruciate ligament reconstruction.J Orthop Res. 2012;30(12):2007-14. doi:10.1002/jor.22176. [PubMed: 22730173].

16. Santello M, McDonagh MJ. The control of timing and amplitude of EMG activity in landing movements in humans. Exp Physiol. 1998;83(6):857-74. [PubMed: 9782194].

17. Sinsurin K, Vachalathiti R, Jalayondeja W, Limroongreungrat W. Knee muscular control during jump landing in multidirections. Asian J Sports Med. 2016;7(2). e31248. doi: 10.5812/asjsm.31248. [PubMed: 27625758]. [PubMed Central: PMC5003310].

18. Croce RV, Russell PJ, Swartz EE, Decoster LC. Knee muscular response strategies differ by developmental level but not gender during jump landing. Electromyogr Clin Neurophysiol. 2004;44(6):339-48. [PubMed: 15473345].

19. Kellis E, Arabatzi F, Papadopoulos C. Muscle co-activation around the knee in drop jumping using the co-contraction index. J Electromyogr Kinesiol. 2003;13(3):229-38. [PubMed: 12706603].

20. Palmieri-Smith RM, Wojtys EM, Ashton-Miller JA. Association between preparatory muscle activation and peak valgus knee angle. $J$ Electromyogr Kinesiol. 2008;18(6):973-9. doi: 10.1016/j.jelekin.2007.03.007. [PubMed: 17498972].

21. Walsh M, Boling MC, McGrath M, Blackburn JT, Padua DA. Lower extremity muscle activation and knee flexion during a jump-landing task. J Athl Train. 2012;47(4):406-13. doi: 10.4085/1062-6050-47.4.17. [PubMed: 22889656]. [PubMed Central: PMC3396300].

22. Aizawa J, Ohji S, Koga H, Masuda T, Yagishita K. Correlations between sagittal plane kinematics and landing impact force during single-leg lateral jump-landings. J Phys Ther Sci. 2016;28(8):231621. doi: 10.1589/jpts.28.2316. [PubMed: 27630422]. [PubMed Central: PMC5011586].

23. Chaouachi A, Padulo J, Kasmi S, Othmen AB, Chatra M, Behm DG. Unilateral static and dynamic hamstrings stretching increases contralateral hip flexion range of motion. Clin Physiol Funct Imaging. 2017;37(1):23-9. doi: 10.1111/cpf.12263. [PubMed: 26017182].

24. Gheller RG, Dal Pupo J, Ache-Dias J, Detanico D, Padulo J, dos Santos SG. Effect of different knee starting angles on intersegmental coordination and performance in vertical jumps. Hum Mov Sci. 2015;42:71-80. doi: 10.1016/j.humov.2015.04.010. [PubMed: 25965000].

25. Padulo J, Tiloca A, Powell D, Granatelli G, Bianco A, Paoli A. EMG amplitude of the biceps femoris during jumping compared to landing movements. Springerplus. 2013;2:520. doi: 10.1186/2193-1801-2-520. [PubMed: 24156093]. [PubMed Central: PMC3797910].

26. McLean SG, Walker KB, van den Bogert AJ. Effect of gender on lower extremity kinematics during rapid direction changes: An integrated analysis of three sports movements. I Sci Med Sport. 2005;8(4):411-22. [PubMed: 16602169].

27. Alenezi F, Herrington L, Jones P, Jones R. The reliability of biomechanical variables collected during single leg squat and landing tasks. JElectromyogr Kinesiol. 2014;24(5):718-21. doi: 10.1016/j.jelekin.2014.07.007. [PubMed: 25128206].

28. Belyea BC, Lewis E, Gabor Z, Jackson J, King DL. Validity and intrarater reliability of 2-dimensional motion analysis using a handheld tablet compared to traditional 3-dimensional motion analysis. J Sport Reha- bil. 2015;24(4). doi: 10.1123/jsr.2014-0194. [PubMed: 25612081].

29. Dingenen B, Barton C, Janssen T, Benoit A, Malliaras P. Test-retest reliability of two-dimensional video analysis during running. Phys Ther Sport. 2018;33:40-7. doi: 10.1016/j.ptsp.2018.06.009. [PubMed: 30005426].

30. Hermens HJ, Freriks B, Disselhorst-Klug C, Rau G. Development of recommendations for SEMG sensors and sensor placement procedures. JElectromyogr Kinesiol. 2000;10(5):361-74. [PubMed: 11018445].

31. Iida Y, Kanehisa H, Inaba Y, Nakazawa K. Role of the coordinated activities of trunk and lower limb muscles during the landing-to-jump movement. Eur J Appl Physiol. 2012;112(6):2223-32. doi: 10.1007/s00421011-2199-2. [PubMed: 21997678].

32. de Britto MA, Carpes FP, Koutras G, Pappas E. Quadriceps and hamstrings prelanding myoelectric activity during landing from different heights among male and female athletes. J Electromyogr Kinesiol. 2014;24(4):508-12. doi: 10.1016/j.jelekin.2014.04.009. [PubMed: 24837628].

33. Falconer K, Winter DA. Quantitative assessment of co-contraction at the ankle joint in walking. Electromyogr Clin Neurophysiol. 1985;25(23):135-49. [PubMed: 3987606].

34. Fauth ML, Petushek EJ, Feldmann CR, Hsu BE, Garceau LR, Lutsch $\mathrm{BN}$, et al. Reliability of surface electromyography during maximal voluntary isometric contractions, jump landings, and cutting. $J$ Strength Cond Res. 2010;24(4):1131-7. doi: 10.1519/JSC.0b013e3181cc2353. [PubMed: 20179648].

35. Yeow $\mathrm{CH}$, Lee PV, Goh JC. Regression relationships of landing height with ground reaction forces, knee flexion angles, angular velocities and joint powers during double-leg landing. Knee. 2009;16(5):381-6. doi: 10.1016/j.knee.2009.02.002. [PubMed: 19250828].

36. Hargrave MD, Carcia CR, Gansneder BM, Shultz SJ. Subtalar pronation does not influence impact forces or rate of loading during a single-leg landing. J Athl Train. 2003;38(1):18-23. [PubMed: 12937467]. [PubMed Central: PMC155506].

37. Elias AR, Hammill CD, Mizner RL. Changes in quadriceps and hamstring cocontraction following landing instruction in patients with anterior cruciate ligament reconstruction. J Orthop Sports Phys Ther. 2015;45(4):273-80. doi: 10.2519/jospt.2015.5335. [PubMed: 25679342].

38. Santello M. Review of motor control mechanisms underlying impact absorption from falls. Gait Posture. 2005;21(1):85-94. doi: 10.1016/j.gaitpost.2004.01.005. [PubMed: 15536038].

39. Hoch MC, Farwell KE, Gaven SL, Weinhandl JT. Weight-bearing dorsiflexion range of motion and landing biomechanics in individuals with chronic ankle instability. J Athl Train. 2015;50(8):833-9. doi: 10.4085/1062-6050-50.5.07. [PubMed: 26067428]. [PubMed Central: PMC4629940].

40. Blackburn JT, Padua DA. Influence of trunk flexion on hip and knee joint kinematics during a controlled drop landing. Clin Biomech (Bristol, Avon). 2008;23(3):313-9. doi: 10.1016/j.clinbiomech.2007.10.003. [PubMed: 18037546].

41. Baratta R, Solomonow M, Zhou BH, Letson D, Chuinard R, D’Ambrosia R. Muscular coactivation. The role of the antagonist musculature in maintaining knee stability. Am J Sports Med. 1988;16(2):113-22. doi: 10.1177/036354658801600205. [PubMed: 3377094].

42. Li G, Rudy TW, Sakane M, Kanamori A, Ma CB, Woo SL. The importance of quadriceps and hamstring muscle loading on knee kinematics and in-situ forces in the ACL. J Biomech.1999;32(4):395-400. [PubMed: 10213029].

43. Yeadon MR, King MA, Forrester SE, Caldwell GE, Pain MT. The need for muscle co-contraction prior to a landing.J Biomech. 2010;43(2):364-9. doi: 10.1016/j.jbiomech.2009.06.058. [PubMed: 19840881].

44. Ford KR, van den Bogert J, Myer GD, Shapiro R, Hewett TE. The effects of age and skill level on knee musculature co-contraction during functional activities: A systematic review. Br J Sports Med. 2008;42(7):561-6. doi: 10.1136/bjsm.2007.044883. [PubMed: 18308891]. [PubMed Central: PMC4006930]. 